\title{
COMUNICAÇÃO ESTRATÉGICA NO CONTEXTO ORGANIZACIONAL
}

\section{STRATEGIC COMMUNICATION IN ORGANIZATIONAL CONTEXT}

\author{
Manuel Joaquim de Sousa Pereira \\ Universidade de Santiago de Compostela \\ E-mail: msousa.manuel@gmail.com
}

\section{RESUMO}

A comunicação estratégica é caracterizada por uma série de planeamento, bem definida e estruturada para alcançar um objectivo global de uma organização. Para construir uma estratégia é necessário ter informações de organizações concorrentes em relação aos seus pontos fortes e fracos, oportunidades e ameaças. Um dos factores diferenciadores das organizações é a capacidade de ouvir, observar e sentir as preocupações, tendências, tendo em conta um valor acrescentado para todos os interessados. Como principal objectivo deste estudo consiste numa análise teórica ao "estado da arte" relativa à comunicação estratégica no contexto organizacional tendo como propósito encontrar as ideias fundamentais sobre esta temática servindo de base a um trabalho mais aprofundado no futuro. Neste sentido, as organizações devem melhorar a capacitação dos funcionários, motivando e incentivando a criatividade, a construção de novos modelos de pensamento que, de forma estratégica, para aprender continuamente em busca do sucesso organizacional.

Palavras-chave: Comunicação estratégica, a participação coletiva, sucesso organizacional, sucesso.

\begin{abstract}
Strategic communication is characterized by a series of planned, well-defined and structured to achieve an overall goal of an organization. To build a strategy is necessary to have information from competing organizations in relation to their strengths and weaknesses, opportunities and threats.

One of the differentiating factors of the organizations is the ability to listen, observe and feel the concerns, trends, taking into account an added value for all stakeholders. As the main objective of this study is a theoretical analysis of the "state of the art" on strategic communication in organizational context with the purpose to find the fundamental ideas on this subject providing the basis for further work in the future.In this regard, organizations should enhance the capacity building of employees, motivating and encouraging creativity, building new models of thought to, in a strategic way, to learn continuously in pursuit of organizational success.
\end{abstract}

Keywords: Strategic communication, collective involvement, efficiency, organizational success 


\section{INTRODUÇÃO}

O conceito de "estratégia" está hoje presente na filosofia organizacional e destina-se a alcançar metas que podem ser comerciais, financeiras, ou políticas. O mundo dos negócios, hoje, caracteriza-se por um conjunto de acções concertadas e planeadas para atingir as suas metas, ou seja, a sua complexidade leva ao estudo, planeamento e implementação de acções concertadas e organizadas para o cumprimento dos objectivos globais da empresa. O conceito de "estratégia" caracteriza-se por ser algo complexo que tem vindo a ser analisado pelos técnicos de comunicação e que continua a querer ser entendido na sua aplicação prática em situações reais, para as quais não existem soluções únicas e universais.

As organizações devem estabelecer um plano de comunicação anual (a ser apresentado ao poder executivo) onde se descrevam as acções concertadas, com a finalidade de atingir um objectivo global, ou seja, não existe um único caminho para atingir determinado fim, daí a complexidade à qual é necessário corresponder com a estratégia mais acertada.

Como principal objectivo deste estudo consiste numa análise teórica ao "estado da arte" relativa à comunicação estratégica no contexto organizacional tendo como propósito encontrar as ideias fundamentais sobre esta temática servindo de base a um trabalho mais aprofundado no futuro.

\section{COMUNICAÇÃO ESTRATÉGICA}

O conceito de estratégia está associado a uma situação problemática de conflito, cuja resolução não se apresenta de forma clara, numa primeira análise, e cujos resultados não são conhecidos, daí a necessidade de estabelecer uma estratégia para encontrar soluções adequadas para atingir os objectivos globais da organização.

Para que se implemente uma estratégia de comunicação é necessário: estabelecer um ou vários objectivos vitais para a organização, pois quando uma instituição não 
tem objectivos bem definidos não sabe o que pretende e, portanto, não precisa de estratégia alguma. Escolher de entre as várias alternativas em análise, a que aparentemente, oferece mais credibilidade. Dado o desconhecimento dos resultados, é necessário estar atento aos agentes concorrentes, estar consciente da limitação dos recursos, para o estabelecimento do plano geral com acções concretas de actuação em função da natureza da situação conflito, que permitam de forma gradual atingir o objectivo final.

Segundo Bond et al., (1999, p. 2), "Strategic communications does not consist of sending out an occasional press release or publishing an op-ed once a year. It means that an organization treats media relations and communications as important, fully integrated, consistent, and ongoing functions and invests resources in it. A strategy, by definition, is "a plain, method, or series of manoeuvres for obtaining a specific goal or result."

Nesta perspectiva, a comunicação estratégica caracteriza-se por ser o conjunto de acções planificadas, bem definidas e estruturadas para atingir um objectivo global de uma organização. A comunicação eficaz é, pois, o conjunto de acções que conduz à mudança de atitudes, alternando comportamentos nos membros da organização, construindo uma linha de orientação forte e abrangente, na qual todos se sintam verdadeiramente motivados e integrados para atingir a meta final.

Para construir uma estratégia é necessário possuir informação das organizações concorrentes, relativamente às suas forças e fraquezas, e oportunidades e ameaças. É necessário obter conhecimento táctico, ou seja, saber quando, onde e de que forma enfrentar o "inimigo", conhecer o estado de espírito do concorrente, para melhor $o$ derrubar $e$ atingir o objectivo proposto, estando sempre atento às alterações do mundo circundante, procurando ajustar constantemente as posições iniciais.

"You should not work in isolation but rather should involve organizational leaders- not just those at top of the flow chart but others who command respect from front-line workers, as well. Look for creativity and out-of-the-box thinking among staff, volunteers, and others who can help" (Ibid.: 4). 
Assim, a comunicação estratégia passa também por envolver toda a organização na sua totalidade, directores, trabalhadores, directores, voluntários, líderes de opinião, e todas as pessoas que se prestarem a ajudar, pois só desta forma, se constrói uma realidade que ultrapassa a perspectiva do técnico de comunicação, na medida em que quantas mais contribuições se apresentarem melhor será o resultado.

Nas palavras de Lamizet \& Silem (1997, P. 142-143) "Communication destinée qui s'inscrit dans une logique d'action et de résultats. La communication stratégique s'ordonne autour de trois modalités, qui caractérisent chacune une certaine approche de la communication par les acteurs qui la mettent en oeuvre.

1 - Modalité symbolique: stratégies de communication appelant une réponse de la part du destinataire, en termes symboliques.

2 - Modalité réelle: injonction, appelant de la part du destinataire un passage à lácte ou une prise de position dans le réel d'une situation.

3 - Modalité imaginaire: séduction, appelant de la part du destinataire un investissement imaginaire sur l'énonciateur ou ce qu'il représenter ».

Nesta perspectiva, a comunicação estratégica está orientada para a acção e a obtenção de resultados, na medida em que o principal objectivo é conseguir transmitir comunicação com significado e com poder simbólico no sentido de gerar acção, ou por outras palavras pretende-se mobilizar comportamentos e atitudes, através do uso das palavras certas, nos momentos certos, para as pessoas certas. A dificuldade, muitas vezes reside, em encontrar o equilíbrio destes factores.

Em termos organizacionais, um dos aspectos fundamentais para que se alicerce 0 sucesso é gerir correcta e eficazmente as pessoas a sua actividade ou a sua maisvalia, estimulando o conhecimento e a aprendizagem, e desta forma, reconhecer competências, aperfeiçoar procedimentos, ajustar os moldes de trabalho às novas realidades, cada vez mais complexas, que exigem naturalmente novas concepção organizacionais e novos desafios. 
Segundo Nonaka (1991, p 93), a organização que aprende e estimula continuamente a capacidade para aprender e conhecer existente no seu interior, 0 que a torna capaz de aperfeiçoar os seus processos e sistemas. Para este autor, aprender é um processo de melhoria de capacidades inseparável da acção, é a capacidade de agir bem, é um "saber-fazer" não é um "saber-saber" e, muito menos, será um "saber-aquilo".

Assim, a organização que procura adquirir novos conhecimentos, descobrir novas formas de organização e gestão, motivando as pessoas, construindo objectivos comuns entre os diferentes públicos, formando uma cultura organizacional, sedimentada na aglutinação do saber teórico com o saber prático, sempre com a necessidade de conhecer e aperfeiçoar o conhecimento consegue adaptar-se de forma mais eficaz às mudanças rápidas e imprevisíveis do ambiente que se verifica no universo empresarial.

Assim, Ribeiro (1998, p. 19) "Actualmente, a cada quatro anos o conhecimento duplica. Dentro de pouco tempo, a partir do ano 2000, duplicará em cada vinte meses. As formas convencionais do saber de aprendizagem e de administração estão obsoletas. O objectivo de hoje, por exemplo, já não pode pretender estar informado sobre tudo o que se produz na sua área de actividade, porque todo o tempo de que dispõe não seria suficiente. A tendência, então, é abrir mais o canal da intuição, o hemisfério direito do cérebro, ampliando a consciência para novas dimensões da inteligência, mais poderosas e subtis."

Segundo este autor, torna-se necessário adquirir conhecimentos mais abrangentes e mais diversificados, estar apto a enfrentar novos desafios, novas concepções, novos mecanismos, novas estruturas organizacionais, quer do ponto de vista humano, quer do ponto de vista técnico.

Uma organização sendo fruto da laboração do homem, está em constante mutação, em constante procura do equilíbrio, na persistente procura da satisfação do prazer de viver, respondendo aos desejos e necessidades dos seus intervenientes, daí que, como as pessoas estão de forma tão rápida, à procura da satisfação de 
necessidades, procuram constantemente, novos desafios, novas formas de viver melhor, num mundo que se pretende mais ajustado às realidades.

Tal como afirma Canavarro (2000, p. 93) "Mais do que a organização de informação que facilita a aprendizagem individual e a integra no seu funcionamento, a organização que aprende tem a capacidade de reflectir sobre si própria e sobre as teorias que guiam a sua acção". Nesta perspectiva, mais do que seleccionar, gerir e controlar informação relevante para atingir os objectivos propostos, é necessário repensar procedimentos, analisar a situação de fora para dentro, possuir uma visão de "helicóptero", abrangente e global, ou seja, ter a capacidade de observar simultaneamente as partes e 0 todo da organização, criando sinergias para que 0 todo seja maior que a soma das partes.

A cooperação dos colaboradores através na elaboração de trabalhos e projectos conjuntos, procurando encontrar soluções conjuntas para um problema concreto da empresa ou organização.

A disponibilização a todos os trabalhadores a possibilidade de dar a opinião ou contribuir com as experiências individuais, percursos de vida, e vivências capazes de, em conjunto, surgirem ideias inovadoras e assertivas na procura de soluções concretas às preocupações contínuas da empresa.

Estabelecer e implementar estratégias na gestão de conflitos, rumores ou mal entendidos entre os trabalhadores, procurando sempre a procura de soluções que conduzam a um ambiente de trabalho agradável e a conjugação dos interesses particulares aos objectivos gerais da organização.

Como estratégia empresarial alguns directores executivos ou presidentes adoptam algumas alterações ou espaços de convívio capaz de fomentar a interacção entre os colaboradores, de forma aleatória ou improvisada, com a funcionalidade de, na hora de almoço, por exemplo, facilitar a comunicação e a troca de impressões entre pessoas, que queiram ou se predisponham a conversar. 
Outras, com o mesmo objectivo, constroem pequenas salas de conferências que tem a finalidade de procurar gerir eventuais conflitos ou divergências entre colaboradores, procurando minimizar situações complicadas ou contribuir para uma melhoria contínua dos interesses e motivações particulares, contribuindo para um ambiente laboral favorável.

Por exemplo e segundo Rego (2007, p. 244) "a Corning Glass mandou instalar escadas, em vez de elevadores (...) para aumentar as chances de as pessoas se encontrarem. A $3 \mathrm{M}$ proporciona clubes de grupos de cerca de uma dezena de empregados, com a finalidade única de aumentar a probabilidade das reuniões improvisadas à hora de almoço e noutras ocasiões."

A própria gestão de pessoas envolve práticas, processos e factores que procuram encontrar soluções consertadas como comunicar de forma clara, directa e objectiva, escutar, discutir ideais, respeitando a diferença de opiniões envolvidas, utilizando a intuição e auto-conhecimento para expressar pensamentos, persuadir e convencer a outra parte.

Sendo utópico imaginar a própria existência de empresas sem conflitos, pois, como os seres humanos sendo seres complexos, necessitam continuamente fazer valer os seus desejos, necessidades, interesses procurando continuamente elevar a auto-estima e em última estância a auto-realização face aos interesses e objectivos globais da própria organização, o que gera quase sempre conflitos de interesse.

\section{COMUNICAÇÃO ESTRATÉGIA NO CONTEXTO ORGANIZACIONAL}

Neste mundo cada vez mais dinâmico e competitivo onde as empresas, mais do que simples operadoras do mercado, devem ser parceiros privilegiados que colaboram, partilham uma sintonia de interesses, a missão e a visão procurando realizar os objectivos.

Assistimos a um conjunto de tendências que reflectem mudanças significativas ao nível cultural, demográfico, político, económico e tecnológico que constituem também 
oportunidades em diferentes áreas para as actuais organizações existentes e para novos empreendedores munidos de novos processos, conhecimentos e modelos de gestão.

Desde modo, verificamos que, por exemplo, a valorização da educação e formação profissional, a internacionalização das organizações e a deslocalização dos trabalhadores para novos locais de trabalho passou a ser uma nova realidade, assim como, o fim do "emprego para toda a vida", pois os trabalhadores precisam acompanhar as dinâmicas mutáveis dos mercados.

Assistimos a alterações significativas ao nível dos comportamentos de consumo, quer seja ao nível dos equipamentos tecnológicos e digitais, entretenimento, bem como, ao nível dos padrões de beleza, onde o emagrecimento, a alimentação equilibrada e o bronzeado da pele passou a ser a realidade.

Ao nível demográfico, assistimos a um aumento generalizado da população mundial, a um aumento da esperança média de vida e um genérico envelhecimento da população na Europa.

Verificamos também que, ao nível político, alterações legais e de normalização para melhor responder aos novos desafios da protecção ambiental, de trabalho, de condições de saúde, de defesa e sensibilização do consumidor contribuindo para a melhoria das condições de vida das pessoas e das comunidades.

Relativamente ao ambiente tecnológico, não param as investigações e a inovação dos produtos de consumo em todas as áreas da vida humana, quer sejam aplicações comerciais, de comunicação, ou produtos ou serviços de consumo.

Para Dolan \& Garcia (2006, p, 65) "Os valores individuais servem como guia das intenções e acções individuais. De igual modo, os sistemas de valor organizacionais orientam os objectivos, políticas e estratégias organizacionais. Desta forma, a natureza dos valores é um factor crucial para o impacto que a cultura terá na eficácia organizacional. Se os valores dominantes apoiam objectivos e estratégias 
apropriadas a cultura constitui um bem importante. Pelo contrário, os valores errados podem tornar a cultura uma grande responsabilidade."

Os valores individuais, segundo o autor, servem de orientação para a mudança, de forma continuada, reflectindo as actividades individuais que constituem uma verdadeira liderança colectiva congruente com os objectivos da própria organização. Um dos factores diferenciadores das empresas reside na capacidade de escutar, observar e sentir as preocupações, tendências e aspirações dos clientes tendo em conta a melhoria da condições do ambiente e da sustentabilidade global, todavia, para isso é preciso criar valor superior aos seus clientes, utilizadores, parceiros e todos os stakeholders.

Segundo Elkjaer (2004, p. 429) e de acordo com Osório, (2009, p. 32). "A organização como sistema ou comunidade de prática é substituída pela organização constituída por universos sociais. O indivíduo não actua como trabalhador independente nem está subjugado à comunidade, podendo, no entanto, estar ou não comprometido na participação de eventos enquanto membro da vida e prática organizacionais (...) A reflexão não é para ser comprometida como um processo mental individual e isolado, mas como parte de uma relação transaccional entre indivíduo (s) e meio ambiente."

Segundo este autor, a organização actua como uma comunidade de indivíduos que partilham reflexões em comunidade interagindo com 0 meio ambiente. Por conseguinte, as organizações devem focalizar a sua acção na eficiência na execução contínua através da motivação para a excelência usando o conhecimento disponível, encorajar a criatividade e agregar os diferentes saberes e experiências. No entanto, uma das formas mais eficientes para melhorar a produtividade passa por atribuir segurança psicológica a todos os colaboradores, procurando que ninguém seja penalização pelo erro, mas pelo contrário, que seja impulsionado a continuar a busca de soluções com as "lições" retiradas dessas mesmas experiências mal sucedidas.

A transferência de conhecimento deve acontecer de forma sistémica, na medida em que o envolvimento das pessoas nos locais de trabalho proporciona um crescimento colectivo e poderá melhorar a produtividade. 
Para Garvin et al., (2008, p, 110) não deixem de referir que a organização aprendente emerge "um ideal ainda não cumprido" devido a um conjunto de factores que têm impedido o seu progresso, nomeadamente o facto de muitas das discussões não passarem de hinos à criação de um mundo melhor em vez de se centrarem nas realidades mais concretas, ou seja, nas práticas próprias das organizações." A criação de um mundo melhor, segundo o autor, é uma pretensão natural de qualquer administração, devendo ser também fundamental acoplar todos os colaboradores evidenciando a sensibilidade compreendendo as diferenças e, acima de tudo, contribuindo continuadamente na procura constante de um "ideal" pensado e ainda não cumprido.

Cada organização procura respostas para compreender os diferentes entendimentos que acontecem internamente, tal como acontece com todos os seres humanos, individualmente ou em grupo, desenvolvem novos processos ou melhoram os que existem através das próprias experiências ou pela experiência de outras pessoas ou organizações.

Como diferença estratégica as organizações devem potenciar a capacidade de criação dos colaboradores, motivando e incentivando a criatividade, construindo novos modelos de pensamento, assim como, aprendendo colectivamente numa perspectiva sistémica de integração.

Segundo Goleman, Boyatzis \& Mckee., (2002, p. 218) "Ao envolver as pessoas num processo de identificação da realidade, os gestores do hospital deram um passo na direcção certa. Reconheceram que os sentimentos das pessoas têm importância e que a cultura tinha de mudar, e proporcionaram condições para que as pessoas pudessem falar como fazer isso. Em consequência, aumentou a energia e o tom tornou-se mais positivo."

O envolvimento das pessoas identificando a realidade, segundo o autor é um factor estrutural para a mudança de atitude e comportamento, pois proporciona condições para abordar os problemas e encontrar as melhores soluções através duma dinâmica de participação e aprendizagem dos seus membros. 
Toda a comunicação positiva expressa através de declarações positivas, de apoio, motivação, apreciação e entusiasmo dado aos colaboradores de uma organização contribui significativamente para a eficiência individual e colectiva da mesma. A positividade organizacional além de melhorar 0 relacionamento entre os colaboradores ao nível do bem-estar físico e psicológico aumenta a auto confiança tornando-os mais criativos e pró-activos capazes de transformar os obstáculos em oportunidades.

As orientações positivas emanadas pelos responsáveis das organizações devem adoptar comportamentos assertivos tais como: ser objectivo e descritivo acerca de acções concretas e quais os comportamentos mais apropriados naquela situação sem ser avaliativo ou punitivo; escutar toda a situação, procurando dar exemplos concretos bem sucedidos; ser congruente e sincero procurando agir em conformidade com as palavras e os gestos; interessar-se pelos problemas das pessoas evitando tecer considerações pessoais; valorizar as pessoas, as suas ideias e pensamentos; assumir toda a acção, escutando atenta e demoradamente as razões de tal comportamento ou atitude e por fim e não menos importante, ser construtivo melhorando o respectivo desempenho.

Aos líderes das organizações sendo responsáveis pelo todo colectivo, devem orientar positivamente quer aspectos negativos e positivos, todavia, precisam de estabelecer um ambiente cordial e de confiança mútua e nas palavras de Rego \& Cunha, (2010, p. 124). "Em suma: importa que os líderes veiculem mensagens positivas, mas também que transmitam as negativas de modo apoiante $\mathrm{e}$ desenvolvimentista. Finalmente: a orientação positiva na transmissão de mensagens negativas é igualmente relevante na interacção com os pares (ajuda a manter o espírito cooperativo e a coordenação do trabalho) e, sobretudo, com os superiores."

Melhorar a cultura da organização através do envolvimento, da participação colectiva e dinâmica, assim como, da constante capacidade de aprender, contribui para uma mudança significativa da organização. Todavia, isto só acontece quando os seus líderes transmitem entusiasmo, inovação, atitude positiva e principalmente 
envolvimento emocional, pois os líderes devem transmitir uma visão do futuro, para ser partilhada por todos os seus colaboradores.

\section{CONCLUSÃO}

A comunicação estratégica tem como princípios gerais estabelecer um conjunto de acções planificadas, bem definidas e estruturadas que levem à mudança de atitudes e comportamentos capazes de construir uma mais-valia para a organização e dessa forma resolver problemas e melhorar a sua performance.

Neste sentido, a comunicação organizacional é estratégica quando envolve todos os colaboradores, alcançando melhores resultados, mobilizando através da comunicação certa, no momento certo e para as pessoas certas, contribuindo dessa forma continuamente para a aprendizagem de dada colaborador em particular e do todo colectivo procurando corresponder aos desafios organizacionais de forma continuada.

Os grandes desafios actuais das organizações passam por procurar constantemente o equilíbrio emocional ao nível de cada colaborador, correspondendo aos seus desejos e necessidades e simultaneamente corresponder às exigências do públicoalvo da própria organização.

A comunicação estratégica estando orientada para a acção, para a pragmatização e a obtenção de resultados, na medida em que o principal objectivo é conseguir transmitir comunicação com significado e com poder simbólico no sentido de gerar acção, ou por outras palavras é mobilizar as pessoas para determinados fins.

Nesta perspectiva, a comunicação só assumirá uma posição estratégica quando inserida num plano de acção comunicacional definido, planeado e concertado no sentido de produzir resultados observados, de uma forma qualitativa ou quantitativa. Em síntese, a comunicação estratégica estando incorporada na dinamização global da organização e estando orientada de forma continuada para a conquista de 
desafios constantes deve procurar corresponder, superando as expetativas de todos os stakeholders.

\section{REFERÊNCIAS BIBLIOGRÁFICAS}

BOND, K. et alii. The jossey-Guide to Strategic Communications for Nonprofits, San Francisco: Jossey Bass Publishers: 1999.

CANAVARRO, J. M. Teorias e Paradigmas Organizacionais. Coimbra: Quarteto, 2000.

CUNHA, M. P., REGO, Arménio, Liderar, Ed. Dom Quixote, 2ª Edição, Alfragide, 2009.

DOLAN, S. L. \& GARCIA, S. Gestão por valores, Ed. BioRumo: Porto, 2006.

GOLEMAN, D.; BOYATZIS, R.; MCKEE, A. Os novos líderes. Ed. Gradiva. 1ª Edição: Lisboa, 2002.

LAMIZET, B. \& SILEM, A. Diccionnaire Encyclopédique des Sciences de Línformation et de la Communication, Paris : Ellipsés, 1997.

OSÓRIO, J. M. P. Learning Organizations: As práticas de gestão de recursos humanos e o papel da cultura organizacional: Universidade do Minho, 2009.

REGO, A. Comunicação Pessoal e Organizacional. Ed. Sílabo: 1a edição, 2007.

REGO, A. \& CUNHA, M. P. Liderança Positiva. Ed. Sílabo. 2ª edição: Lisboa, 2010.

RIBEIRO, L. Comunicação Global. Ed. Pergaminho: Lisboa, 1998.

ROBBINS, S. P. O segredo na gestão de pessoas. Ed. Centro Atlântico. 1a edição: Lisboa, 2008. 
Recebido: 20/09/2013

Aprovado: 17/08/2014 